\title{
Novel small Cajal-body-specific RNAs identified in Drosophila: probing guide RNA function
}

\author{
SVETLANA DERYUSHEVA ${ }^{1}$ and JOSEPH G. GALL ${ }^{1}$ \\ Department of Embryology, Carnegie Institution for Science, Baltimore, Maryland 21218, USA
}

\begin{abstract}
The spliceosomal small nuclear RNAs (snRNAs) are modified post-transcriptionally by introduction of pseudouridines and $2^{\prime}$-Omethyl modifications, which are mediated by box H/ACA and box C/D guide RNAs, respectively. Because of their concentration in the nuclear Cajal body (CB), these guide RNAs are known as small CB-specific (sca) RNAs. In the cell, scaRNAs are associated with the WD-repeat protein WDR79. We used coimmunoprecipitation with WDR79 to recover seven new scaRNAs from Drosophila cell lysates. We demonstrated concentration of these new scaRNAs in the CB by in situ hybridization, and we verified experimentally that they can modify their putative target RNAs. Surprisingly, one of the new scaRNAs targets U6 snRNA, whose modification is generally assumed to occur in the nucleolus, not in the CB. Two other scaRNAs have dual guide functions, one for an snRNA and one for $28 \mathrm{~S}$ rRNA. Again, the modification of $28 \mathrm{~S}$ rRNA is assumed to take place in the nucleolus. These findings suggest that canonical scaRNAs may have functions in addition to their established role in modifying U1, U2, U4, and U5 snRNAs. We discuss the likelihood that processing by scaRNAs is not limited to the CB.
\end{abstract}

Keywords: Cajal body; RNA modification; scaRNA; WDR79 protein

\section{INTRODUCTION}

Post-transcriptional modifications in spliceosomal small nuclear RNAs (snRNAs) and ribosomal RNAs (rRNAs) are essential for spliceosome assembly and splicing competency (Yu et al. 1998; Donmez et al. 2004; Zhao and Yu 2004, 2007; Yang et al. 2005; Karijolich and Yu 2010) as well as for the assembly of functional ribosomal subunits and the efficiency and fidelity of translation (Lapeyre 2005; Liang et al. 2007, 2009; Esguerra et al. 2008; Jack et al. 2011). Two common alterations in these RNAs, namely, pseudouridylation and $2^{\prime}$-O-methylation, are usually mediated by the so-called modification guide RNAs, the box H/ACA and box C/D RNAs, respectively. For review of the discovery and general features of guide RNAs, see Maxwell and Fournier (1995), Smith and Steitz (1997), and Yu et al. (2005). These RNAs were typically identified in isolated nucleoli or nucleolar extracts and were called small nucleolar RNAs, or snoRNAs. Because of the colocalization of snoRNAs with newly transcribed rRNAs in the nucleolus, it was assumed that the modifications themselves take place in the nucleolus. The first guide RNAs for spliceosomal snRNA modification, namely, for U6 snRNA 2'-O-methylation, were also identified in a nucleolar fraction. Furthermore, one of these guide RNAs was

\footnotetext{
${ }^{1}$ Corresponding authors

E-mail gall@ciwemb.edu

E-mail deryusheva@ciwemb.edu

Article published online ahead of print. Article and publication date are at http://www.rnajournal.org/cgi/doi/10.1261/rna.042028.113.
}

found to modify both U6 snRNA and 28S rRNA (Tycowski et al. 1998). Later experiments showed that U6 snRNA fragments could be modified when they were specifically targeted to the nucleolus (Ganot et al. 1999).

When guide RNAs for 2'-O-methylation and pseudouridylation of U1, U2, U4, and U5 snRNAs were discovered, they were found to concentrate not in the nucleolus but in another nuclear organelle, the Cajal body (CB). Because of their localization, these guide RNAs were referred to as small CB-specific RNAs, or scaRNAs (Darzacq et al. 2002; Kiss et al. 2002, 2004; Richard et al. 2003). Detailed analysis of scaRNA structure revealed short motifs that mediate the targeting of scaRNAs to CBs. These CB-specific localization signals are referred to as CAB boxes (Richard et al. 2003; Tycowski et al. 2009). CBs themselves were first described in neurons more than 100 years ago (Cajal 1903). In recent years, they have been found in a wide variety of tissue and cell types in all eukaryotic species that have been carefully examined. CBs are usually recognized by a high concentration of coilin, a marker protein of unknown function. Along with coilin and scaRNAs, CBs are enriched for splicing snRNAs and the core components for modification guide RNP assembly (Liu et al. 2009; Nizami et al. 2010a). The accumulation of snRNAs and their

(C) 2013 Deryusheva and Gall This article is distributed exclusively by the RNA Society for the first 12 months after the full-issue publication date (see http://rnajournal.cshlp.org/site/misc/terms.xhtml). After 12 months, it is available under a Creative Commons License (Attribution-NonCommercial 3.0 Unported), as described at http://creativecommons.org/licenses/by-nc/ $3.0 \%$ 
corresponding guide RNAs in the same nuclear organelle immediately led to the idea that U1, U2, U4, and U5 snRNAs are modified in the CB. Indeed, fragments of U2 and U5 snRNAs became modified when they were targeted to CBs, but not when targeted to nucleoli (Jády et al. 2003). In contrast, U6 snRNA, whose known guide RNAs concentrate in nucleoli (Tycowski et al. 1998; Ganot et al. 1999; Darzacq et al. 2002), could not be modified when targeted to CBs (Jády et al. 2003). The postulate that snRNA modification requires targeting to CBs became untenable when it was shown that snRNA modification still takes place in mutant cells that lack CBs (Deryusheva and Gall 2009; Nizami et al. 2010b; Deryusheva et al. 2012). Furthermore, snRNAs can be efficiently modified in vitro in cell-free systems (Jády and Kiss 2001; Ma et al. 2005; Deryusheva and Gall 2009). The question remains, however, why guide RNAs for snRNA modification often concentrate in CBs when that localization is not required for function.

The WD-repeat protein WDR79 has been identified recently in Drosophila and human cells as a protein that specifically binds to the CAB box in scaRNAs and is required for scaRNAs to concentrate in CBs (Tycowski et al. 2009; Venteicher et al. 2009). Tycowski et al. (2009) have shown that endogenous scaRNAs can be coprecipitated efficiently with WDR79 protein from both human and Drosophila cells. We decided to use this approach for identification of novel scaRNAs in Drosophila. In previous studies nine $2^{\prime}$-O-methylated residues and 15 pseudouridines were detected in Drosophila U1, U2, U4, and U5 snRNAs (Myslinski et al. 1984; Huang et al. 2005; Deryusheva and Gall 2009). Although most or all of these modifications are probably directed by guide RNAs, only seven scaRNAs have been described so far in Drosophila (Jády and Kiss 2001; Deryusheva and Gall 2009; Tycowski et al. 2009). Here we use coimmunoprecipitation of WDR79RNA complexes followed by RNA extraction and cDNA analysis to identify more scaRNAs in Drosophila. We found seven new scaRNAs that interact with WDR79 protein, possess CAB-box motifs, and concentrate in CBs. Surprisingly, among the newly identified scaRNAs, we found a box H/ ACA RNA that base-pairs with U6 snRNA. Moreover, two other scaRNAs from our screen form pseudouridylation pockets that can base-pair with $28 \mathrm{~S}$ rRNA and are capable of positioning the predicted modifications. The finding of these unexpected guide RNAs poses again the question of where post-transcriptional modification of snRNAs and rRNAs occurs in the nucleus and why scaRNAs concentrate in CBs.

\section{RESULTS}

\section{WDR79 constructs}

Drosophila WDR79 is a WD-repeat protein that interacts with the CAB box, a short motif found in scaRNAs (Tycowski et al. 2009). In wild-type flies, WDR79 is concentrated in CBs, where it colocalizes with scaRNAs. Despite the close associa- tion of WDR79 with scaRNAs and CBs, this association is not essential: Flies that are null for WDR79 protein lack CBs in all their cells but are otherwise apparently normal (Nizami et al. 2010b). In the following experiments, we used the interaction between WDR79 and scaRNAs in a wild-type background to verify seven previously identified scaRNAs and to discover seven new ones. Because the antibody we use for immunolocalization of WDR79 does not efficiently precipitate the protein, we made two RFP-tagged WDR79 constructs, expressed these as transgenes in flies, and used an anti-RFP antibody to immunoprecipitate WDR79 protein (Fig. 1A). In the first construct, RFP was at the carboxyl terminus of WDR79; in the second, it was at the amino terminus. In both cases, UASp was included as the most upstream element, so that WDR79 protein could be induced by GAL4 expression. Unexpectedly, the WDR79-RFP transgene expressed effectively without GAL4 induction in seven different transgenic lines. Importantly, the transgenic protein showed wild-type distribution in several different tissues, including Malpighian tubules (Fig. 1B,C), ejaculatory duct, and both germline and follicle cells in the ovary. Moreover, this transgene could rescue the formation of CBs in WDR79-null flies (Fig. 1E,F). At the same time, overexpression induced by GAL4 led to disassembly of CBs in wild-type flies (Fig. 1D). Unlike WDR79-RFP, the RFP-WDR79 construct required GAL4 induction as expected (Fig. 1H), yet without GAL4, this construct could express untagged WDR79 (Fig. 1H) and rescue the WDR79-null phenotype (Fig. 1G).

These and other data suggested that the annotation for Drosophila WDR79 was originally incomplete and that the annotated protein-coding cDNA sequence might contain a promoter. Using 5'-RACE, we detected eight transcription start sites for endogenous WDR79. These sites were different for RNA isolated from males and females, but all concentrated in a 31-nucleotide (nt) region at position 102-132 of the annotated WDR79 cDNA. The annotated mRNA is expressed as a minor fraction that appears to be testis-specific (Fig. 2).

\section{Immunoprecipitation of previously known scaRNAs}

In the earlier study of Drosophila scaRNAs (Tycowski et al. 2009), the WDR79 protein that was used to coprecipitate scaRNAs was the putative testis-specific isoform, Flag-tagged at the amino terminus. We carried out immunoprecipitation experiments with extracts from several different fly lines. First, we used flies that express WDR79-RFP from an endogenous promoter, which gives a normal level of expression from a predominantly shorter isoform. Second, we used flies that express WDR79-RFP and RFP-WDR79 from the UAS promoter driven by daGAL4. In both these cases, WDR79 expression levels are above normal and formation of CBs is disturbed (Fig. 1D).

We found that all seven of the known Drosophila scaRNAs coprecipitated equally well with WDR79-RFP and RFPWDR79 proteins. Moreover, the interaction does not depend 
A GAL4 induced transcription
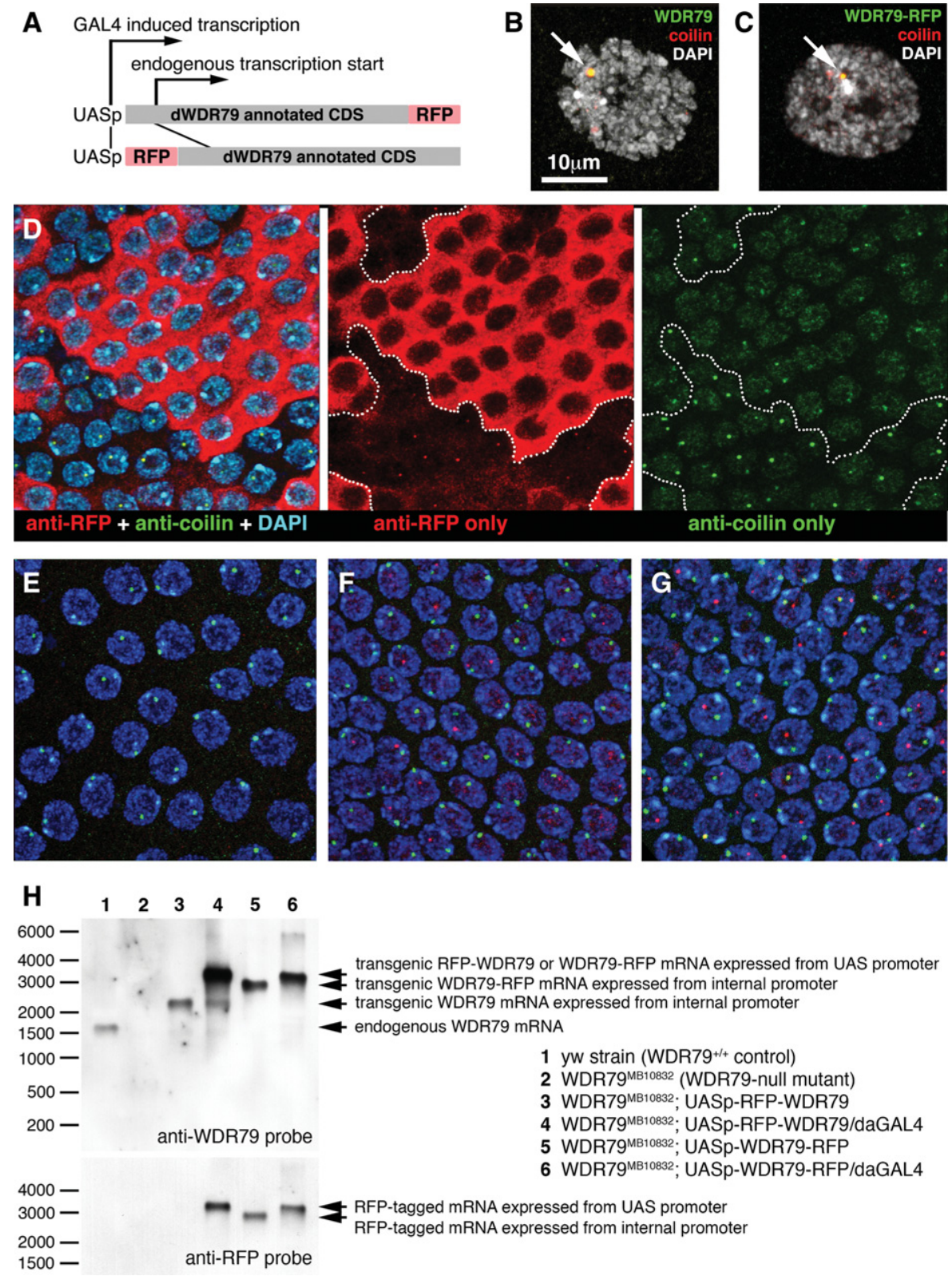

FIGURE 1. Transgenic WDR79 protein behaves like endogenous WDR79 in Drosophila, and it rescues the WDR79-null phenotype. (A) Diagram of the two major WDR79 constructs used in this study. In each case, the annotated WDR79 transcript is shown in gray. Both constructs include an RFP sequence, one at the carboxyl terminus, the other at the amino terminus. Each includes an upstream UASp sequence for expression under control of GAL4. Both constructs express without GAL4 induction from an endogenous promoter within the cloned WDR79 sequence, although expression is enhanced by GAL4. (B) Endogenous WDR79 (green), detected with an antibody against the protein itself, colocalizes with coilin (red), producing a yellow Cajal body (CB) in the nucleus of a Malpighian tubule cell from a $y w$ fly (arrow). (C) WDR79-RFP protein (green) expressed without GAL4 induction, detected with an antibody against RFP, also colocalizes with coilin (red) in the CB (arrow). (D) Ovarian follicle cells from WDR79-RFP/ daGAL4 flies, stained for RFP (red) and coilin (green). Because of UAS-GAL4 variegation, two types of expression patterns are observed in the same tissue. In some cells, WDR79-RFP is overexpressed from the UAS promoter and accumulates in the cytoplasm; in most of these cells, nuclear CBs are not detectable. The remaining cells express WDR79-RFP at a lower level from the endogenous promoter. In these cells, WDR79-RFP accumulates with coilin in the CB in the nucleus. Viability of the cells seems to be unaffected by overexpression of WDR79-RFP. (E-G) Both WDR79-RFP and RFPWDR79 transgenes can rescue the formation of CBs in WDR79-null flies. Ovarian follicle cells from WDR79-null flies $(E)$ or from WDR79-null flies that express WDR79 from transgenes $(F, G)$, stained for coilin (red) and Lsm 11 (green). None of these flies carried a GAL4 driver, so expression is from an endogenous WDR79 promoter. The transgene in $F$ is WDR79-RFP, whose transcript includes the RFP tag; that in G is RFP-WDR79, whose transcript begins downstream from the tag. Cells from WDR79-null flies lack CBs $(E)$. Hence, their nuclei display histone locus bodies (green Lsm 11 foci), but CBs are undetectable (no red coilin foci). On the other hand, cells that express either WDR79-RFP $(F)$ or WDR79 alone $(G)$ may have CBs (red coilin foci) in addition to histone locus bodies (green Lsm11 foci). (H) Northern blot analysis of WDR79 mRNA expressed in $y w$ (control) and WDR79 ${ }^{M B 10832}$ (mutant) flies. mRNA is expressed from the endogenous gene in $y w$ flies and from transgenes in the mutant background. WDR79 mRNA is undetectable in RNA extracted from WDR79 ${ }^{M B 10832}$ mutant flies, suggesting that this is a null mutation. 


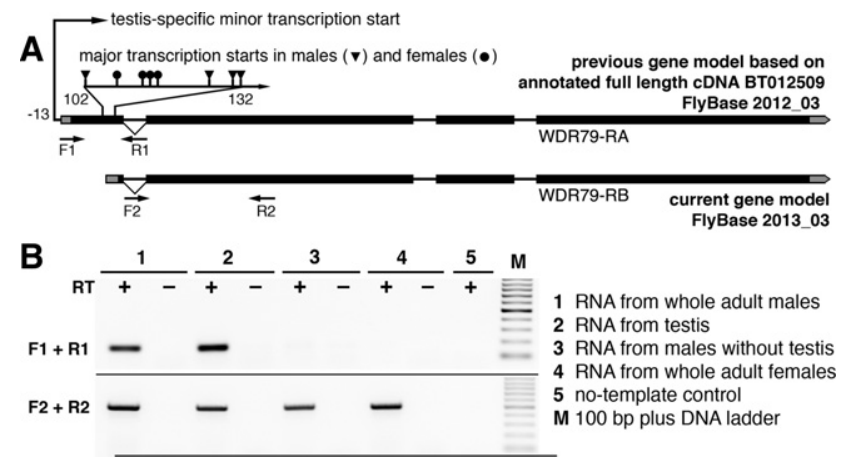

FIGURE 2. (A) Gene models of Drosophila WDR79. When we started this project the gene model for WDR79 was based on cDNA clone BT012509, annotated as a full-length mRNA sequence (WDR79-RA). The current gene model is based on RNA-seq analysis (WDR79-RB). Multiple transcription starts that we determined by $5^{\prime}$-RACE are in a good agreement with the current gene model. At the same time, a transcription start corresponding to the earlier annotation was also detected in RNA isolated from males. (Short arrows) Oligonucleotide primers used for RT-PCR analysis to detect different isoforms of WDR79 mRNA. (B) RT-PCR of WDR79 mRNA (using primers shown in A) reveals different isoforms in male and female tissues.

on the level of WDR79 expression or even on the formation of typical CBs in the cells of the flies. The top two rows of Figure 3A show RT-PCR fragments of two known scaRNAs, U85 and mgU4-65, detected in the various immunoprecipitates. The other five known Drosophila scaRNAs were similarly detected (mgU2-25, mgU2-28, mgU2-41, mgU5-38, and mgU5-42). One more reported Drosophila scaRNA, Dm46E3 (Tortoriello et al. 2009), was undetectable in our samples.

The specificity of the interaction between WDR79 and the scaRNAs was confirmed by showing that several snoRNAs did not coprecipitate with WDR79. The tested snoRNAs included predicted guide RNAs for 2'-O-methylation and pseudouridylation of $28 \mathrm{~S}$ rRNA and for $2^{\prime}$-O-methylation of U6 snRNA. Results for three of these snoRNAs are shown in Figure 3A (mgU6-47, pug28S-3327, and mg28S-3344). Similar negative results were obtained for two additional snoRNAs (mgU6-68 and pug28S-3186). These snoRNAs do not have CAB-box motifs and do not concentrate in CBs. They do, however, concentrate in nucleoli, as verified by FISH with antisense probes (Fig. 3C shows mgU6-47).

Spliceosomal snRNAs are substrates for scaRNA-mediated post-transcriptional modifications and are present at high concentration in CBs, along with both WDR79 and scaRNAs. Nevertheless, they are not enriched after immunoprecipitation of WDR79 (Fig. 3A, U4 snRNA). Similar results were found in the earlier study by Tycowski et al. (2009). These data suggest that WDR79 binds specifically to scaRNAs but does not interact with snRNAs.

\section{New Drosophila scaRNAs}

The seven previously known Drosophila scaRNAs direct eight of 24 known modifications in U1, U2, U4, and U5 snRNAs
(U85 scaRNA directs two modifications). To find more RNAs that specifically interact with WDR79, including scaRNAs, we prepared a cDNA library from RNA that coprecipitated with WDR79-RFP protein. To avoid artifacts due to overexpression, we used a fly stock in which WDR79-RFP was expressed at a normal level from the endogenous promoter and rescued the $\mathrm{CB}$ phenotype of a WDR79-null mutant (Fig. 1F,H). It is worth noting that we did not obtain any clone that contained spliceosomal snRNA sequences. In addition to six of the known scaRNAs, we found seven novel small RNAs derived from introns of protein-coding genes (Table 1). We verified the existence of these small RNAs by Northern blot analysis in both wild-type and WDR79-null flies (Fig. 3B). We also demonstrated their enrichment in WDR79 co-IP samples. Rows 3-6 in Figure 3A show RT-PCR fragments for four of these (pugU1-6, pugU2-55, mgU2-48, and pugU6-40). Three others were similarly detected (pugU2$35 / 45$, pugU2-38/40/42, and pugU5-44). Finally, we showed by FISH that these RNAs concentrate in CBs and are thus scaRNAs by definition (Fig. 3C). We deposited the nucleotide sequences of these RNAs in GenBank; the corresponding accession numbers are listed in Table 1. These RNAs were detected previously in a genome-wide Drosophila transcriptome analysis using deep sequencing (Graveley et al. 2011), but they were not characterized as CB-specific guide RNAs.

The newly identified small RNAs could be folded into typical box H/ACA or box C/D RNA structures. Analysis of these structures allowed us to identify CAB-box motifs in all seven new scaRNAs, in good agreement with their interaction with WDR79 protein and their concentration in CBs. We analyzed potential antisense elements in these RNAs for matches with major and minor spliceosomal snRNAs, as well as for matches with rRNA. The results of this search are summarized in Table 1 and Figure 4.

\section{Probing new scaRNAs for guide RNA activity}

We have tested the seven new scaRNAs for modification activity in three ways, two involving intact Xenopus oocytes or extracts of Xenopus oocyte nuclei (Deryusheva and Gall 2009) and the third making use of transformed Saccharomyces cerevisiae cells.

We first tested the seven new scaRNAs for modification activity in extracts of Xenopus oocyte nuclei (previously depleted for all RNAs). This assay involves mixing the guide RNA with its corresponding presumed substrate and then analyzing for modification of the substrate by a primer extension reaction. Only two guide RNAs were functional in this test, pugU1-6 and pugU2-38/40/42 (Fig. 5A,B; Table 1). We consider only positive results to be significant in this in vitro assay, since there are many reasons that a modification reaction involving a Drosophila scaRNA might not take place in a heterologous Xenopus nuclear extract.

The second use of Xenopus involves injection of a guide RNA along with its putative unmodified substrate into a 
A
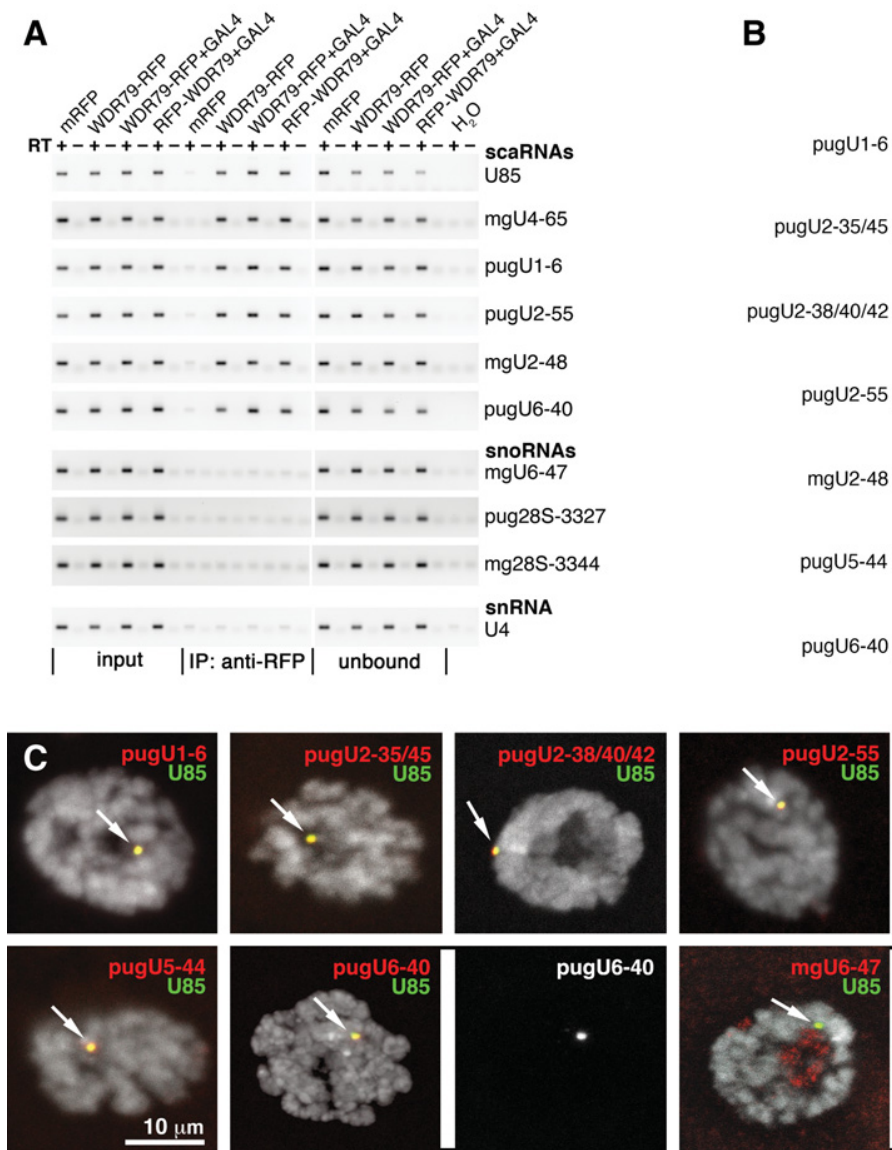

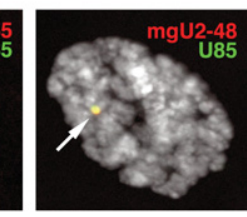

B
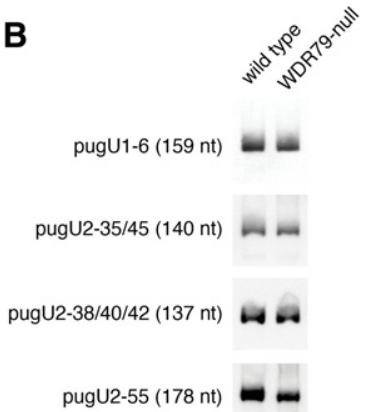

$\mathrm{mgU} 2-48(125 \mathrm{nt})$

pugU6-40 (141 nt)

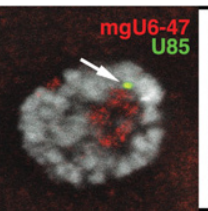

pugU5-44 (139 nt)

FIGURE 3. WDR79 transgenic protein interacts with scaRNAs in Drosophila. (A) RT-PCR analysis to demonstrate the specific association of scaRNAs with WDR79 protein. An antibody against RFP was used to immunoprecipitate RNA-protein complexes from flies that expressed RFP-labeled WDR79. The first four columns show RT-PCR analysis for the input extracts, the second four columns for the immunoprecipitate, and the final four columns for the supernatant after immunoprecipitation. The first six rows show that two previously known scaRNAs (U85 and mgU4-65) as well as four previously unknown scaRNA are detectable in the immunoprecipitate. snoRNAs and U4 snRNA are abundant in the input extract but are not found in the immunoprecipitate. None of the tested RNAs are immunoprecipitated from extracts of flies that express RFP alone (columns labeled mRFP). (B) All seven new scaRNAs coprecipitated with WDR79 are detectable by Northern blot analysis in total RNA extracted from wild-type flies (first lane) and from flies that are null for WDR79 protein (second lane). These scaRNAs express at similar levels in mutant and wild-type flies. $(C)$ All seven new scaRNAs are detectable by in situ hybridization in nuclei of Malpighian tubule cells, where they colocalize with U85, a well-established marker for the CB (arrows). The localization of pugU6-40 in the $\mathrm{CB}$ (second and third panels in the bottom row) contrasts sharply with the localization of mgU6-47 in the nucleolus (last two panels in the bottom row). Note that the CB is green (U85 signal) in the mgU6-47 panel, whereas it is yellow in the other panels (U85 + new scaRNA).

living oocyte, followed after a suitable time by a primer extension reaction to detect modification of the substrate. This is a limited assay because one must first deplete the oocyte of any endogenous guide activity. We have analyzed only one putative guide RNA by this method, a box H/ACA RNA that we designated Drosophila pugU2-35/45. This is the ortholog of the well-characterized human U92 (Darzacq et al. 2002) and Xenopus laevis pugU2-34/44 (Zhao et al. 2002). The latter can be efficiently depleted from Xenopus oocytes by injecting an antisense oligonucleotide (Zhao et al. 2002).

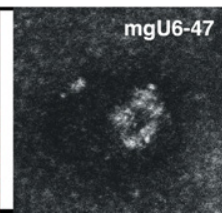

We first injected unmodified Drosophila U2 snRNA into oocytes that had been depleted for Xenopus pugU2-34/ 44, an ortholog of Drosophila pugU2-35/ 45. In this control experiment, we expected to see no pseudouridines at positions 35 and 45 in the injected Drosophila U2, but normal pseudouridylation at positions modified by other endogenous Xenopus scaRNAs (positions 38, 40, 42, and 44). Instead, we saw a normal level of modification at position 35, strongly reduced modification at position 45, and complete loss of modification at position 44 (Fig. 5C, red trace). Modification at position 35 is probably due to the activity of an endogenous pseudouridine synthase (Pus7p) that can catalyze pseudouridylation at position 35 of Drosophila U2 snRNA (or the equivalent position 34 in vertebrates). Such an activity is known from many species including Xenopus and Drosophila (Ma et al. 2003; Karijolich and Yu 2010).

The situation at positions 44 and 45 is more difficult to interpret. Coinjection of Drosophila pugU2-35/45 restores the normal pattern of pseudouridines, with a very strong signal at position 45 and a somewhat weaker one at position 44 (Fig. 5C, blue trace). One interpretation is that pugU2-35/45 can modify both positions 44 and 45 . Another interpretation is that a separate pseudouridine synthase exists for position 44 and that its activity is influenced by the presence or absence of pugU2-35/45. Such a synthase (Pus1p) has been identified in yeast (Massenet et al. 1999), and its orthologs are presumably responsible for the corresponding modification in higher eukaryotes (Behm-Ansmant et al. 2006).

For further analysis of Drosophila scaRNAs in living cells, we expressed various constructs in the yeast $S$. cerevisiae. One can express Drosophila scaRNAs on a plasmid in yeast and look for modification of endogenous yeast snRNAs. Alternatively, one can coexpress the scaRNAs along with Drosophila artificial substrates and look for modification of the substrates. Yeast offers a favorable system because of the relatively low level of endogenous snRNA modification. There are no 2'-O-methylations in any of the snRNAs, but, importantly, yeast cells have the ability to support this type of modification, since their rRNAs are methylated. There are relatively few pseudouridines (Massenet et al. 1999). No 
TABLE 1. Novel scaRNAs of Drosophila: predicted modifications in snRNAs and rRNA and results of three modification assays

\begin{tabular}{|c|c|c|c|c|c|c|c|}
\hline \multirow[b]{2}{*}{ Guide RNA } & \multirow[b]{2}{*}{ Host gene } & \multirow[b]{2}{*}{ Accession number } & \multicolumn{2}{|c|}{ Predicted modification } & \multicolumn{3}{|c|}{ Guide RNA activity in modification assay } \\
\hline & & & Target RNA & Position & GV extract & Xenopus oocytes & Yeast cells \\
\hline \multirow{3}{*}{$\begin{array}{l}\text { Pseudouridylation } \\
\text { pugU1-6 }\end{array}$} & & & & & & & \\
\hline & $d m t$ & JQ963649 & U1 snRNA & 6 & + & $\mathrm{n} / \mathrm{a}$ & $\mathrm{n} / \mathrm{a}$ \\
\hline & & & $28 \mathrm{~S}$ rRNA & $2838^{\mathrm{a}}$ & - & $\mathrm{n} / \mathrm{a}$ & + \\
\hline \multirow[t]{2}{*}{ pugU2-35/45 } & gp210 & JQ963645 & U2 snRNA & 35 & - & $?$ & + \\
\hline & & & & 45 & - & + & + \\
\hline \multirow[t]{3}{*}{ pugU2-38/40/42 } & bur & JN409597 & U2 snRNA & 38 & + & $\mathrm{n} / \mathrm{a}$ & + \\
\hline & & & & 40 & - & $\mathrm{n} / \mathrm{a}$ & + \\
\hline & & & & 42 & + & $\mathrm{n} / \mathrm{a}$ & + \\
\hline \multirow[t]{2}{*}{ pugU2-55 } & prp8 & JQ963646 & U2 snRNA & 55 & - & $\mathrm{n} / \mathrm{a}$ & + \\
\hline & & & $28 \mathrm{~S}$ rRNA & $1960^{\mathrm{a}}$ & - & $\mathrm{n} / \mathrm{a}$ & + \\
\hline pugU5-44 & tra2 & JQ963650 & U5 snRNA & 44 & - & $\mathrm{n} / \mathrm{a}$ & $\mathrm{n} / \mathrm{a}$ \\
\hline pugU6-40 & skd & JQ963648 & U6 snRNA & 40 & - & $\mathrm{n} / \mathrm{a}$ & + \\
\hline \multicolumn{8}{|l|}{$2^{\prime}-O-M e t h y l a t i o n$} \\
\hline $\mathrm{mgU} 2-48$ & $p U f 68$ & JQ963647 & U2 snRNA & 48 & - & $\mathrm{n} / \mathrm{a}$ & + \\
\hline
\end{tabular}

${ }^{a}$ These positions are not modified in Drosophila 28S rRNA (Ofengand and Bakin 1997; data not shown).

(+) Modification was detected at the position predicted by the corresponding scaRNA.

(-) Modification was not detected at the predicted position.

(?) Assay was inconclusive for the predicted modification.

(n/a) Not analyzed.

modifications have been detected in yeast U4 and U6. Only three pseudouridines are normally found in $\mathrm{U} 2$ at positions 35,42 , and 44 of the highly conserved branch point recognition region. Corresponding mutant strains are available for each of these positions. Two pseudouridines are known for $\mathrm{U} 1$ at positions 5 and 6 . Finally, there is a pseudouridine at position 99 in U5, although the mechanism of its modification has not been determined (Massenet et al. 1999). Overall, when our new Drosophila scaRNAs were expressed in yeast cells, they were capable of modifying the predicted positions in endogenous yeast $\mathrm{U} 2$ or the corresponding artificial substrates coexpressed in the same cells (Figs. 6, 7; Table 1). We were not able to test our pugU1-6 and pugU5-44 because of the endogenous modifications at the corresponding positions in yeast (position 6 in $\mathrm{U} 1$ and position 99 in U5). We discuss three of the new Drosophila scaRNAs in more detail because they illustrate some unexpected features.

\section{pugU2-35/45}

Because the pseudouridylation pocket in the pugU2-35/45 Drosophila scaRNA is somewhat degenerate for modification at position 35 of U2 snRNA, we would not have been surprised to find it nonfunctional. However, expression of pugU2-35/45 in Pus7p-deficient yeast cells (pus7 4 ) resulted in pseudouridylation of the endogenous yeast U2 (Fig. 6, top two traces). The situation at position 45 is more complicated. Because of sequence divergence between yeast and Drosophila U2 at position 45 (Fig. 4, second row), we expected that position to be modified inefficiently. Indeed, this was the case when pugU2-35/45 was expressed in either wildtype or pus7 7 yeast strains. However, when pugU2-35/45 was expressed in the pus $1 \Delta$ strain (lacking pseudouridylation at position 44), position 45 of the endogenous yeast U2 became intensely modified (Fig. 6, third and fourth traces). These observations allowed us to exclude position 44 as a potential substrate for pugU2-35/45 modification. At the same time, they showed that an imperfect pocket for positioning pseudouridine at position 45 in yeast U2 snRNA can be fully functional under the appropriate circumstances.

\section{pugU2-38/40/42}

The pugU2-38/40/42 guide RNA provides another example of a fully functional but noncanonical pseudouridylation pocket. When we first assayed this guide RNA in the Xenopus GV extract, we saw the expected pseudouridylation at position 42 of U2 snRNA, slight modification at position 38, but no modification at the strongly predicted position 40 . In fact, the same domain that forms the pseudouridylation pocket for position 40 can, when refolded, base-pair with U2 to form a pocket for position 38. However, in this configuration, not 2 but 3 nt remain unpaired in the substrate RNA (Fig. 4, third row). When yeast cells that lacked the guide RNA for pseudouridylation at position 42 (snr81 $\Delta$ ) were transformed with a plasmid expressing Drosophila pugU2-38/40/42, we saw rescue of pseudouridylation at position 42 as expected (Fig. 6, sixth trace). We also saw unambiguous modification at position 38 . However, only a minor signal was detectable at position 40 . This signal became more prominent when modification at position 42 was prevented by expressing a mutated pugU2-38/40/42 $\Delta$ that lacked the guide element for that position. In addition, modification at position 40 became more prominent when pugU2-38/40/42 was 


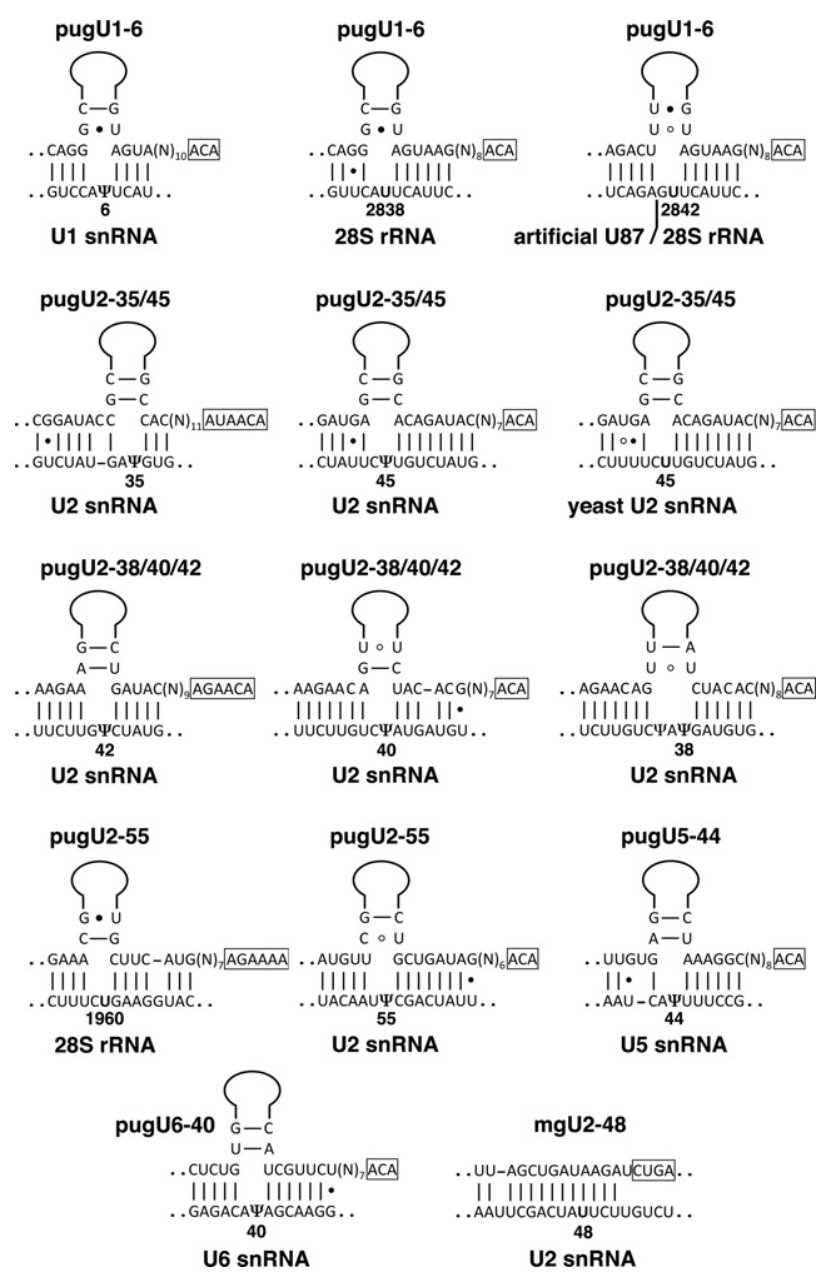

FIGURE 4. Postulated base-pairing between novel Drosophila scaRNAs and their substrates: Drosophila spliceosomal snRNAs U1, U2, U5, U6, yeast U2, and two regions in Drosophila 28S rRNA.

expressed in the pus $7 \Delta$ yeast strain, which cannot modify position 35 (Fig. 6 , fifth trace).

\section{pugU1-6}

The most striking example of guide-substrate plasticity was observed when we tested the ability of pugU1-6 scaRNA to modify the fragment of $28 \mathrm{~S}$ rRNA inserted in huU87 RNA. In this case, two pseudouridines were clearly detectable in the artificial substrate, as if an additional target for the guide RNA had been accidentally created (Fig. 7, bottom two traces). Formation of the pocket for this second pseudouridylation produces a quite unstable stem-loop structure (Fig. 4, first row), which would never be predicted by standard free-energy-based RNA folding software.

In summary, our analysis of Drosophila scaRNAs in yeast and Xenopus verified nine of 10 predicted "conventional" modifications of snRNAs and two unexpected modifications of $28 \mathrm{~S}$ rRNA. In addition, we experimentally demonstrated modifications by a guide RNA with imperfect antisense ele- ments (pugU2-35/45), by a guide RNA with a dual pseudouridylation pocket preferentially functional in a noncanonical configuration (pugU2-38/40/42), and by a guide RNA that functioned with an unusual folding pattern (pugU1-6). Finally, we demonstrated that a genuine scaRNA (pugU640) can modify its putative target in U6 snRNA.

\section{DISCUSSION}

\section{New scaRNAs}

The major finding of our study is the identification of seven new scaRNAs in Drosophila in addition to the seven previously

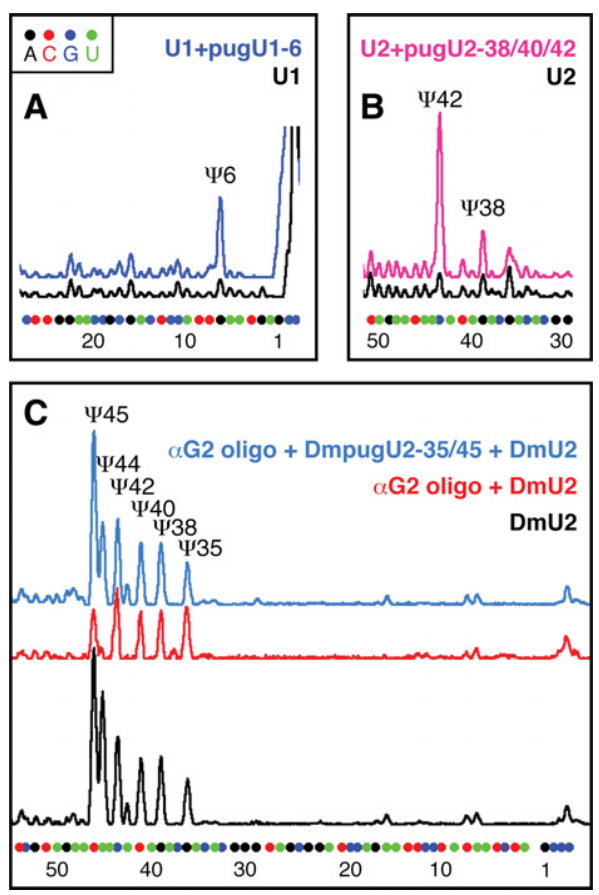

FIGURE 5. Drosophila scaRNAs in RNA modification assays based on Xenopus oocytes. (A) Pseudouridylation of Drosophila U1 snRNA mediated by pugU1-6 in RNA-depleted GV extract. When in vitro-transcribed U1 snRNA was added to the extract along with guide RNA pugU1-6 (blue trace), a prominent peak corresponding to pseudouridine at position 6 was detected compared with the control reaction in which only U1 snRNA was added (black trace). (B) Pseudouridylation of Drosophila U2 snRNA mediated by pugU2-38/40/42 in RNA-depleted GV extract. Addition of the guide RNA and in vitro-transcribed U2 snRNA (red trace) produced a prominent peak corresponding to pseudouridine at position 42 , a moderately increased peak at position 38 , but no appreciable change at other positions. The black trace shows a control reaction without the guide RNA. (C) Pseudouridylation of Drosophila U2 snRNA injected into Xenopus oocytes. When in vitro-transcribed Drosophila U2 was injected alone as a control, pseudouridines at positions $35,38,40$, 42,44 , and 45 were clearly detected (black trace). When Xenopus pugU2-34/44 guide RNA was depleted by injecting antisense oligonucleotide $\alpha \mathrm{G} 2$, pseudouridylation at positions 44 and 45 was dramatically reduced (red trace). When pre-depleted oocytes were supplemented with Drosophila guide RNA pugU2-35/45, pseudouridylation was restored at positions 44 and 45 (blue trace). In panels $A-C$ the colored dots denote the positions of A (black), C (red), G (blue), and U (green) determined from control sequencing reactions on in vitro-transcribed RNA. 
known. The approach we used was to immunoprecipitate the WDR79 protein from lysates of fly tissue and to look for scaRNAs in the precipitate. We identified all seven of the previously known scaRNAs by RT-PCR. Importantly, we showed that the immunoprecipitate did not contain snRNAs, which are both abundant in the nucleus and concentrated in the $\mathrm{CB}$, the same nuclear organelle where the scaRNAs are concentrated. New scaRNAs were identified in a cDNA library prepared from the immunoprecipitate and were verified by Northern blot analysis of Drosophila RNA. To make sure that all the new RNAs met the definition of an scaRNA, we demonstrated their presence in the CB by in situ hybridization on Drosophila tissues. Thus, they are scaRNAs by virtue of their nuclear localization as well as their association with WDR79.

We used three systems to verify the function of the newly identified scaRNAs: an extract of Xenopus GVs, injection into Xenopus oocytes, and expression from exogenous plasmids in yeast. We verified that six of the seven newly identified scaRNAs can function as guide RNAs for modification of other RNAs at the predicted positions (Table 1). The exception is pugU5-44, which did not modify U5 snRNA in an extract of Xenopus GVs and could not be tested in yeast.

\section{Unusual guide functions}

A surprise was the demonstration of pugU6-40 among the RNAs associated with WDR79. As with all the new RNAs, we verified that it is concentrated in the CB by in situ hybridization and meets the cytological definition of an scaRNA (Fig. $3 \mathrm{C}$ ). Furthermore, it mediates the pseudouridylation of position 40 in U6 snRNA in a yeast assay. Guide RNAs for this modification have also been identified in human (ACA12 and HBI-100), mouse (MBI-100 and MBI-114), and a wide variety of other vertebrate species (Huttenhofer et al. 2001; Kiss et al. 2004; Lestrade and Weber 2006). Although there are no FISH data for these vertebrate guide RNAs, they have been annotated as scaRNAs based on the possession of CAB-box motifs (Lestrade and Weber 2006) (http://wwwsnorna.biotoul.fr/). In addition, human ACA12, HBI-100, and ACA65 (which presumably directs U6 pseudouridylation at positions 31 and 86) coprecipitate with WDR79 protein (Tycowski et al. 2009). Thus, there is good reason to suppose that the situation in Drosophila is not unique and that some positions in mammalian U6 snRNA are modified by canonical scaRNAs. How is this observation to be reconciled with the general consensus that modification of U6 snRNA takes place in the nucleolus? One possibility is that modification of U6 snRNA requires shuttling between the $\mathrm{CB}$ and the nucleolus. Alternatively, the fact that a guide RNA is concentrated in either the nucleolus or the CB may be misleading. High concentration makes the organelle prominent after FISH, but need not correlate with total amount in the nucleus. It is known, for instance, that both coilin-null and WDR79-null flies lack cytologically detectable CBs, yet they have normal levels of scaRNAs and their snRNAs are normally modified (Deryusheva and Gall 2009; Nizami et al. 2010b). The clear implication is that the majority of modification either occurs normally in the nucleoplasm or at least can occur there when the CBs missing. For reasons specific to the nucleolus-it is a gene locus and not a "free-floating" organelle-the comparable ablation experiment cannot be carried out. Nevertheless, it remains possible that snoRNAs are concentrated in the nucleolus and function there primarily because that is the only place where their rRNA substrate resides. The site of U6 snRNA modification may be more flexible because the substrate is free to move about in the nucleus, being found in the nucleolus, the $\mathrm{CB}$, or the nucleoplasm.

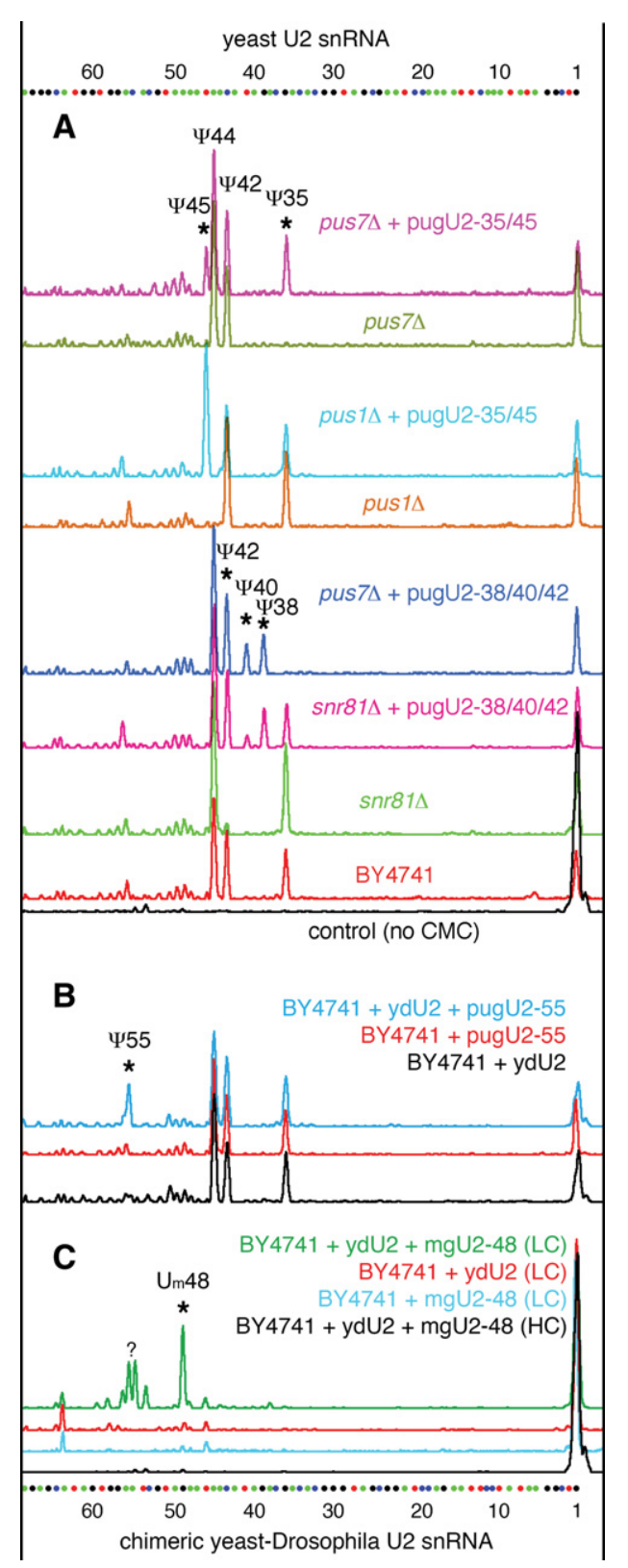

FIGURE 6. (Legend on next page) 
We found two unusual scaRNAs with dual modification functions, pugU1-6 and pugU2-55. pugU1-6 modifies position 6 in Drosophila U1 snRNA in GV extract, but it also can modify position 2838 in Drosophila $28 \mathrm{~S}$ rRNA in a yeast assay. Similarly, pugU2-55 modifies position 55 in Drosophila U2 snRNA as well as position 1960 in Drosophila 28S rRNA, both in yeast assays. Although the modifications in U1 and U2 snRNA occur normally in Drosophila and other organisms, modifications at positions 2838 and 1960 of Drosophila rRNA have not been detected (Ofengand and Bakin 1997). It is possible that the modifications in rRNA somehow result from use of an exogenous assay system. It is known, for instance, that guide RNA snR81 of yeast concentrates in the nucleolus and directs modifications in yeast U2 snRNA and 25S rRNA (Ma et al.2005). Alternatively, scaRNAs may recognize noncanonical substrates only under certain conditions, such as in certain tissues or under special circumstances. Such an example is known from yeast, where two pseudouridines in U2 snRNA appear only under stress conditions (Wu et al. 2011).

Our analysis demonstrates an unexpected degree of plasticity between guide RNAs and their substrates. The canoni-

FIGURE 6. Modification of U2 snRNA mediated by Drosophila scaRNAs in the yeast $S$. cerevisiae. (A) Endogenous yeast U2 snRNA is normally pseudouridylated at positions 35,42 , and 44 (RNA from reference strain BY4741). Mutant strains that are deficient for Pus1p, Pus7p, or guide RNA snR81 show the absence of pseudouridylation at position

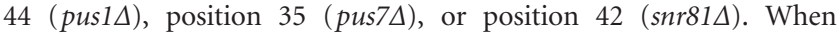
Drosophila guide RNA pugU2-35/45 is introduced into the pus7 $\Delta$ strain (pus7 $\Delta+$ pugU2-35/45), it rescues pseudouridylation at position 35 (star) and additionally induces modification at position 45 (star). The pseudouridylation at position 45 is much more prominent when pugU2-35/45 is expressed in the pus1 $\Delta$ strain (pus1 $\Delta+$ pugU2-35/45). Similarly, expression of Drosophila pugU2-38/40/42 in the snr81 $\Delta$ strain

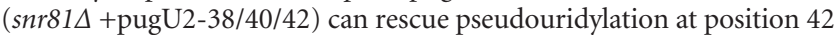
(star), and additionally positions 38 and 40 (stars) become modified. Pseudouridylation at position 40 is weak in wild type, pus1 1 (data not shown) and snr81 $\Delta$ strains but appears more prominent when pugU2-38/40/42 is expressed in the pus7 $\Delta$ strain (pus7 $\Delta+$ pugU2-38/ 40/42). Control primer extension reactions without CMC treatment were run on all RNA samples. They showed no stop signals, as observed for RNA from the BY4741 strain. (B) Only three pseudouridines are detectable in U2 snRNA from BY4741 yeast cells that express either Drosophila pugU2-55 guide RNA (BY4741 + pugU2-55, red trace) or its substrate chimeric yeast-Drosophila U2 (ydU2) snRNA alone (BY4741 + ydU2, black trace). However, an extra peak (star) corresponding to pseudouridine at position 55 in Drosophila U2 snRNA appears when both pugU2-55 guide RNA and its substrate are coexpressed in the same yeast strain (BY4741+ydU2 + pugU2-55, blue trace). (C) Expression of Drosophila mgU2-48 guide RNA in yeast cells induces $2^{\prime}-O$-methylation at position 48 in coexpressed chimeric yeast-Drosophila U2 snRNA (star, top green trace). Extra stop signals of unknown origin (question mark) were observed in this trace, where the primer extension reaction was performed at a low concentration (LC) of dNTP. No stop signals were produced in control reactions run at high concentration (HC) of dNTPs with the same RNA sample (black trace) or at low concentration with RNA extracted from yeast cells that express only one of the two exogenous RNAs: either mgU2-48 (blue trace) or chimeric yeast-Drosophila U2 snRNA (red trace). Alignment with U2 snRNA sequences is shown with colored dots as in Figure 5 (yeast U2 snRNA at the top of the figure and chimeric yeast-Drosophila U2 snRNA at the bottom).

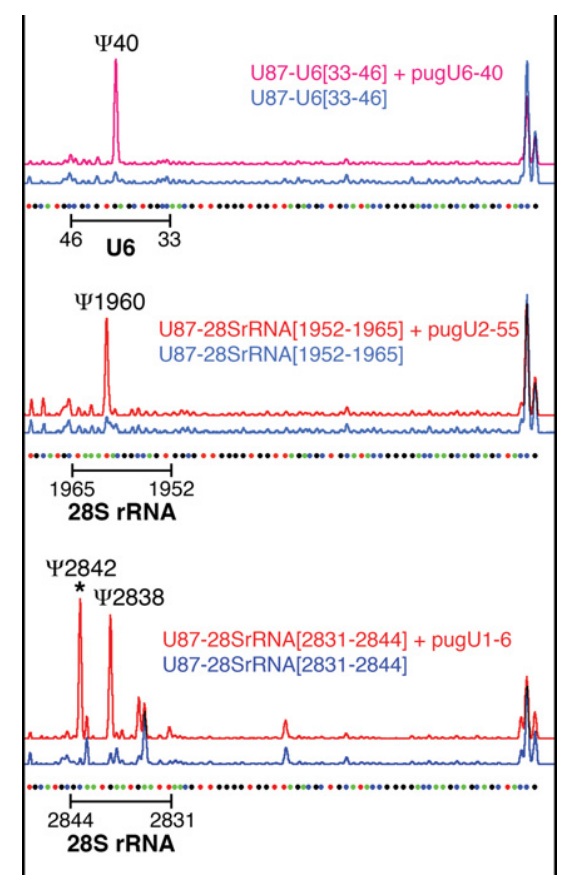

FIGURE 7. Modification of artificial substrates mediated by Drosophila scaRNAs in yeast. Artificial RNAs were constructed by inserting the predicted targets for Drosophila scaRNAs into human U87 scaRNA. These were expressed in wild-type yeast cells either alone (blue traces) or along with their corresponding guide RNAs (red traces). When RNA from these transformed yeast strains was tested in primer extension reactions, pseudouridines at the expected positions were detected ( $\Psi 40$ in U6, $\Psi 1960$ and $\Psi 2838$ in 28 S rRNA). Surprisingly, an additional strong signal was observed at $\Psi 2842$ (star) with pugU1-6. The base-pairing between pugU1-6 and the artificial $28 \mathrm{~S}$ substrate required for this modification is shown in Figure 4. Sequences are color-coded with dots as in Figure 5. The inserted target sequences from U6 snRNA and $28 \mathrm{~S}$ rRNA are underlined.

cal pseudouridylation pocket involves a region of perfect base-pairing between the guide RNA and its substrate, surrounding two unpaired nucleotides, one of which is the target uridine. We showed that in living cells box H/ACA RNAs (pugU2-35/45, pugU2-38/40/42, and pugU1-6) can support pseudouridylation of substrate RNAs that differ significantly from this model (Fig. 4). Moreover, the conserved stemloop-stem region of the snoRNA itself can vary considerably. These observations suggest that numerous box H/ACA snoRNAs that have been reported as "orphans" may be functional guide RNAs (e.g., Hüttenhofer et al. 2001; Kiss et al. 2004).

\section{The function of WDR79 protein}

In this study, we used the specific interaction of WDR79 protein with scaRNAs as a means to enrich for the latter. We presume that additional immunoprecipitation experiments could be used to identify still more scaRNAs, since there remain at least seven additional modifications in Drosophila snRNAs for which the corresponding guide RNAs have not 
been described. Our experiments do not, however, address several important questions about the interaction of these molecules in the cell. The notion that WDR79 binds to scaRNAs by means of the CAB box and targets them to their snRNA substrates in the $\mathrm{CB}$, where the modification reactions occur, is too simplistic. In fact, neither WDR79 protein nor $\mathrm{CBs}$ themselves are required for post-transcriptional modification of Drosophila snRNAs. We showed earlier that Drosophila scaRNAs can function without the CAB box, suggesting that WDR79 does not necessarily play a direct role in the modification reaction (Deryusheva and Gall 2009). Later we confirmed this conclusion by demonstrating normal snRNA modification (Nizami et al. 2010b) and normal levels of scaRNAs in WDR79-null flies (Fig. 3B). These flies completely lack cytologically detectable CBs. Furthermore, there is evidence that the association of WDR79 with the CAB box is not limited to CBs. The recently identified human Alu-repeat box H/ACA-like RNAs contain CAB-box motifs and interact with WDR79 protein, but they do not accumulate in CBs (Jády et al. 2012). In our experiments, overexpression of WDR79 protein in transgenic flies causes disassembly of CBs (Fig. 1D), yet does not affect WDR79 binding to scaRNAs (Fig. 3A). In summary, the scaRNAs may need to associate with WDR79 for targeting to CBs, but that association is not sufficient for CB localization, nor is it required for snRNA modification.

\section{Concluding remarks}

The analysis of new scaRNAs in Drosophila underscores the necessity to verify the putative guide function(s) of newly isolated or predicted guide RNAs. Bioinformatics predictions, especially base-pairing, provide strong circumstantial evidence of scaRNA function. Nevertheless, our analysis demonstrates that not all predicted modifications occur with high efficiency and that some scaRNAs can carry out unexpected reactions. It is also clear that the relationship between WDR79, scaRNAs, and CBs is not simple, since modification reactions occur normally in flies that lack both WDR79 and CBs. When present in the cell, WDR79 interacts preferentially with scaRNAs and mediates targeting to the $\mathrm{CB}$, but neither the interaction nor the targeting is necessary for scaRNA function or for viability of the organism. Finally, the ability of scaRNAs to modify U6 snRNA and rRNA suggests that the traditional sharp distinction between snoRNAs and scaRNAs cannot be maintained in its simplest form.

\section{MATERIALS AND METHODS}

\section{Fly stocks}

Drosophila melanogaster stocks were maintained at room temperature $\left(21^{\circ} \mathrm{C}-23^{\circ} \mathrm{C}\right)$ on a standard cornmeal-based medium.
Transgenic flies

The annotated full-length protein coding sequence for Drosophila WDR79 was amplified from the cDNA clone AT03686. This was first cloned into the Gateway entry vector pENTR/D-TOPO (Invitrogen). It was then swapped into the pPRW or pPWR vector to make Pelement constructs in which protein expression is under control of the yeast upstream activating sequence (UASp) and the expressing protein has an RFP-tag at either the amino or carboxyl terminus, respectively. Injections into Drosophila embryos were done by Genetic Services. Seventeen transgenic lines with random insertions of WDR79 cDNA were obtained: 10 lines with RFP at the amino terminus and seven lines with RFP at the carboxyl terminus.

\section{Other fly stocks}

$y w$ served as a control strain. For a WDR79-null background, we used $\left[w^{1118} ; M i\{E T 1\} W D R 79^{M B 10832}\right]$ (Bloomington \#29159). As a negative control for anti-RFP immunoprecipitation assays, we used a line that expresses $\mathrm{MRFP}$ with a nuclear localization signal under the ubiquitin promoter $\left[w^{1118} ; P\{U b i-m R F P . n l s\} 3 L P\{n e o F R T\} 80 B\right]$ (Bloomington \#30852). A stock that expresses GAL4 from the daughterless promoter (daGAL4) was used to drive UASp-WDR79 transgenes in all tissues.

\section{RNA extraction and PCR-based analysis}

RNA was extracted from whole flies, isolated testes, or male carcasses from which the testes had been removed manually. Either the RiboPurekit or the RNAqueous Micro kit (Ambion) was used depending on the sample size. RNA samples were treated with RNase-free DNase I (Ambion) when used for RT-PCR. RT-PCR was performed using the One-Step RT-PCR Kit (QIAGEN). All amplified fragments were sequenced to verify the specificity of the RT-PCR.

To detect the $5^{\prime}$ end of Drosophila WDR79 mRNA, we used the FirstChoice RLM-RACE Kit (Ambion). We followed the recommended protocol, including tobacco acid pyrophosphatase (TAP)minus reactions as negative controls. The $3^{\prime}$-gene-specific primers annealed either to exon 2 (to detect major mRNA variants) or to a region upstream of major transcription start sites (to detect testisspecific mRNA). PCR products were cloned into the pGEM-T Easy vector (Promega) and sequenced.

\section{Northern blot analysis}

RNA samples were separated either on formaldehyde agarose gels (for mRNAs) or on $8 \%$ polyacrylamide- $8 \mathrm{M}$ urea gels (for small RNAs). The RNA was transferred onto a nylon membrane (Zeta Probe GT, Bio-Rad) and probed with single-stranded antisense DNA labeled with digoxigenin (DIG)-dUTP. DIG was detected using an anti-DIG antibody conjugated with alkaline phosphatase and the chemiluminescent substrate CDP-Star (Roche) according to the manufacturer's protocols.

\section{Western blot analysis and immunofluorescent staining}

Western blot analysis of Drosophila protein extracts was performed according to standard procedures. Whole-mount immunofluorescent staining of various Drosophila tissues was as previously 
described (Liu et al. 2009). In both cases, the primary antibodies were the same: an affinity-purified rabbit polyclonal antibody generated against an 18-amino-acid peptide corresponding to residues 136153 of the predicted Drosophila WDR79 protein, guinea pig antibodies against Drosophila coilin (Liu et al. 2009), rabbit anti-RFP either unconjugated or HRP-conjugated (MBL Medical and Biological Laboratories Co., Ltd.), or mouse anti-a-tubulin (clone DM1A, Sigma-Aldrich). Secondary antibodies for Western blots were conjugated with HRP, whereas those for tissue immunostaining were conjugated with Alexa 488, Alexa 594, or Alexa 633 fluorescent dyes. Antibodies were used at a dilution of 1:30,000 in 5\% nonfat dry milk for Western blots and 1:1000 in 10\% horse serum for immunofluorescent staining.

\section{Fluorescent in situ hybridization (FISH)}

Fluorescent RNA probes were labeled with Alexa 488-UTP or Cy5CTP in in vitro transcription reactions using DNA clones or PCR products as templates. These dyes were chosen to obtain complete separation of fluorescent signals when two-color FISH was used for colocalization analysis. The procedure for whole-mount FISH on Drosophila tissues was described previously (Deryusheva and Gall 2009). Images were captured using a laser-scanning confocal microscope (Leica SP2 or SP5) with a $63 \times$ (NA 1.40) planapochromatic objective. Images were taken with the laser intensity and photomultiplier gain adjusted to avoid saturated pixels in the region of interest ("glow-over" display). In some cases, the relative intensities and colors of the channels were adjusted with Photoshop (Adobe).

\section{Immunoprecipitation}

For each coimmunoprecipitation (co-IP) reaction, 50-60 pairs of Drosophila ovaries were manually dissected in ice-cold Grace's medium. Cells were lysed in $500 \mu \mathrm{L}$ of protein extraction buffer $(50 \mathrm{mM}$ Tris- $\mathrm{HCl}$ at $\mathrm{pH} 7.5,150 \mathrm{mM} \mathrm{NaCl}, 5 \mathrm{mM} \mathrm{MgCl}, 0.1 \%$ NP-40) supplemented with Protease and Phosphatase Inhibitor Cocktail (Roche) and RNasin (Promega). Lysates were precleared using protein $\mathrm{G}$ agarose beads (Roche). Then $3 \mu \mathrm{L}$ of anti-RFP antibody was added, and the lysates were incubated for $1 \mathrm{~h}$ at $4^{\circ} \mathrm{C}$. To capture the immunocomplexes, protein $\mathrm{G}$ agarose beads were added, and the incubation was continued for another $1 \mathrm{~h}$ (beads were pre-blocked with bovine serum albumin and calf intestinal alkaline phosphatase-treated yeast tRNA). After incubation, the beads were washed five times with $1 \mathrm{~mL}$ of the protein extraction buffer. To determine the efficiency of the WDR79 IP, immunocomplexes were dissociated from the beads by boiling in sample buffer and then subjected to Western blot analysis. RNA was extracted from the beads with the RiboPure kit (Ambion).

RNA samples from co-IP reactions were treated with RNase-free DNase I and used for RT-PCR. Oligos specific for Drosophila scaRNAs and snRNAs were as previously described (Deryusheva and Gall 2009). To make a cDNA library of RNAs to which WDR79 protein binds, RNA released from the beads was decapped and polyadenylated, and $5^{\prime}$ and $3^{\prime}$ adapters were added (FirstChoice RLM-RACE Kit). cDNA fragments were amplified using $5^{\prime}$ - and $3^{\prime}$ RACE primers from the same kit. The resulting PCR products were cloned into the pGEM-T Easy vector, and 96 randomly picked colonies were sequenced. To verify the $5^{\prime}$ and $3^{\prime}$ ends of newly identi- fied small RNAs, a standard RACE procedure was performed on total RNA isolated from whole flies of the $y w$ strain.

\section{RNA sequence analysis}

An initial prediction of scaRNA folding was carried out using the Mfold web server (http://mfold.rna.albany.edu/). Secondary structures predicted by the software were then analyzed and adjusted manually. Putative antisense elements were screened for matches with all regions of Drosophila spliceosomal snRNAs and rRNAs.

\section{In vitro modification assays}

Full-length coding sequences of Drosophila scaRNAs were amplified from genomic DNA and ligated into the pGEM-T Easy vector. A T3 promoter was included in the forward primer upstream of the first coding nucleotide; a BamHI site was included in the reverse primers immediately following the last coding nucleotide. Plasmids were linearized with BamHI, and sense-strand RNAs were transcribed using T3 RNA polymerase. The same strategy was used to clone fragments of Drosophila 28S rRNA; specific oligos were designed to amplify regions 1904-2062 and 2747-3055 in 28S rRNA. In vitrotranscribed snRNAs were made from previously described constructs of Drosophila U1, U2, U4, and U5 snRNAs (Deryusheva and Gall 2009). The coding sequence of Drosophila U6 snRNA was also cloned.

An in vitro modification assay based on a Xenopus oocyte nuclear extract was previously described (Deryusheva and Gall 2009). Briefly, 150 nuclei (germinal vesicles or GVs) were manually isolated and collected in mineral oil. The nuclei were centrifuged to disrupt the nuclear envelope and sediment nuclear organelles, and the resulting extract was treated with micrococcal nuclease (New England Biolabs) to destroy endogenous RNA. The nuclease was then inactivated by adding EGTA. Finally, an in vitro-transcribed snRNA or rRNA was added to the nuclear extract along with its putative guide RNA. RNA was extracted after $6-12 \mathrm{~h}$ of incubation, and the substrate RNA was tested for modification(s) introduced by the guide RNA.

In a second assay based on Xenopus oocytes, an in vitro-transcribed guide RNA (Drosophila pugU2-35/45) was injected into the GV and an in vitro-transcribed snRNA (Drosophila U2) into the cytoplasm (Deryusheva and Gall 2009). First, however, it was necessary to destroy the endogenous guide RNA pugU2-34/44. To do this, $230 \mathrm{ng}$ of a DNA oligonucleotide, aG2 (GTATCTGTCGT CATCAA), was injected into the cytoplasm and the oocyte was incubated overnight (Zhao et al. 2002). Then Drosophila U2 snRNA and its corresponding guide RNA, pugU2-35/45, were injected, and the oocytes were incubated a further 6-7 h. Finally, nuclei were manually isolated and the Drosophila U2 snRNA was tested for modification.

\section{Expression of Drosophila guide RNAs and their substrates in yeast}

pugU2-35/45 and pugU2-38/40/42

The pugU2-35/45 and pugU2-38/40/42 guide RNAs reside in the introns of Drosophila gp210 and bur genes, respectively. Fragments that contained the guide RNAs and the flanking exons were 
amplified from genomic DNA of $y w$ flies. XmaI and XhoI restriction sites were added to the fragments, which were then cloned into the yeast $\mathrm{p} 425 \mathrm{Gall}$ vector.

\section{mgU2-48, pugU2-55, and pugU1-6}

Constructs were made in which Drosophila mgU2-48 replaced a box C/D snoRNA (snR18) in the yeast EFB1 gene, and Drosophila pugU2-55 or pugU1-6 replaced a box H/ACA snoRNA (snR191) in the yeast NOG2 gene. In each case, overlap extension PCR was used to carry out the replacement. Fragments of the yeast genes were amplified from genomic DNA of the BY4741 yeast strain; $\mathrm{XmaI}$ and XhoI restriction sites were included in the primers. The Drosophila scaRNAs were amplified from genomic DNA of $y w$ flies. The chimeric fragments resulting from the overlap extension PCR were digested with XmaI and XhoI and cloned into the yeast p425Gall vector.

pugU6-40, pugU2-35/45, pugU2-38/40/42, and pugU2-38/40/42D

The coding sequences of the pugU6-40, pugU2-35/45, pugU2-38/ 40/42, and pugU2-38/40/42 $\Delta$ Drosophila guide RNAs were cloned into the YEplac181 vector, which contains a GPD promoter, an RNT1 cleavage site, and an snR13 terminator (Huang et al. 2011) (a gift from Yi-Tao Yu, University of Rochester Medical Center). pugU2-38/40/42 $\Delta$ is a variant guide RNA with a mutated pseudouridylation pocket for position 42 .

\section{Modified yeast U2 snRNA}

Sequences from Drosophila U2 snRNA were introduced into the yeast U2 snRNA gene as follows. A plasmid containing the yeast U2 snRNA gene with a unique EcoRI site at the $5^{\prime}$ end was cut with EcoRI and EcoNI and religated with a fragment of the Drosophila U2 gene (nucleotides 9-70 with EcoRI and EcoNI sites immediately flanking the coding sequence). The yeast U2 plasmid pRS316[URA3 CEN SNR20] was a gift from Yi-Tao Yu.

Substrates for Drosophila pugU6-40, pugU2-55, and pugU1-6

A fragment of Drosophila U6 snRNA (nucleotides 33-46) and two fragments of Drosophila 28S rRNA (nucleotides 1952-1965 and 2831-2844) were inserted into the human U87 scaRNA by replacing nucleotides 210-217. A somewhat similar strategy was used by Jády et al. (2003). In addition, a lower-complexity substrate was made by deleting the H/ACA domain (nucleotides 27-183) of human U87 scaRNA. These six chimeric sequences were then substituted for snR18 in the EFB1 gene and cloned into the p426Gall vector.

The various constructs described above were introduced into yeast $S$. cerevisiae by the standard lithium acetate method. Wild type (BY4741) and three mutant strains (pus1 $\Delta$, pus7 $\Delta$, and snr81A) were used. Expression of Drosophila scaRNAs under the Gall promoter was obtained by growing cells for $24 \mathrm{~h}$ in appropriate selective media with galactose as a source of sugar. Expression and processing of the exogenous RNAs were verified by Northern blot analysis.

\section{Primer extension-based modification analysis}

2'-O-Methylation and pseudouridylation were analyzed by fluorescent primer extension assays as described (Deryusheva and Gall 2009). Single-stranded DNA fragments were separated using a capillary electrophoresis instrument (ABI Prism 3100 Genetic Analyzer). The Gene Scan-500 Liz Size Standard (Applied Biosystems) was included in each sample.

Oligonucleotides for Drosophila U1, U2, U4, and U5 snRNA modification mapping were previously described (Deryusheva and Gall 2009); in vitro-transcribed U6 snRNA was analyzed using an oligonucleotide: ATACGACTCACTATAGGATCCAAAA. To analyze yeast U2 snRNA, an oligonucleotide complementary to nucleotides 99-125 was used: GGGTGCCAAAAAATGTGTATTGTAA CA. Drosophila $28 \mathrm{~S}$ rRNA was probed for modification using two oligonucleotides: [2009-2033] CCGAGGAGAAAATATCGACACAA CA and [2986-3022] TTATACCAAATTTTCAAATCAAAAATACA TAAATGCA. Artificial substrates inserted into the huU87 sequence were analyzed using an oligonucleotide complementary to the $3^{\prime}$ end of huU87: AGGTCTCAGATTGAAAACTTGAGATCA.

\section{ACKNOWLEDGMENTS}

We thank Jeff Han and Irena Martirosyan (Carnegie Institution) and Yi-Tao Yu and Guowei Wu (University of Rochester Medical Center) for providing yeast strains and plasmids, sharing reagents, and teaching us how to work with yeast. We thank Allison Pinder for expert technical help. The research reported in this publication was supported by the National Institute of General Medical Sciences of the National Institutes of Health under award number R01GM33397 to J.G.G. The content is solely the responsibility of the authors and does not necessarily represent the official views of the National Institutes of Health. J.G.G. is American Cancer Society Professor of Developmental Genetics.

Received August 16, 2013; accepted September 23, 2013.

\section{REFERENCES}

Behm-Ansmant I, Massenet S, Immel F, Patton JR, Motorin Y, Branlant C. 2006. A previously unidentified activity of yeast and mouse RNA:pseudouridine synthases 1 (Pus1p) on tRNAs. RNA 12: $1583-1593$.

Cajal SR. 1903. Un sencillo metodo de coloracion selectiva del reticulo protoplasmatico y sus efectos en los diversos organos nerviosos de vertebrados e invertebrados. Trab Lab Invest Biol Univ Madrid 2: $129-221$.

Darzacq X, Jády BE, Verheggen C, Kiss AM, Bertrand E, Kiss T. 2002. Cajal body-specific small nuclear RNAs: A novel class of 2'-Omethylation and pseudouridylation guide RNAs. EMBO J 21: 27462756.

Deryusheva S, Gall JG. 2009. Small Cajal body-specific RNAs of Drosophila function in the absence of Cajal bodies. Mol Biol Cell 20: 5250-5259.

Deryusheva S, Choleza M, Barbarossa A, Gall JG, Bordonne R. 2012. Post-transcriptional modification of spliceosomal RNAs is normal in SMN-deficient cells. RNA 18: 31-36.

Donmez G, Hartmuth K, Lührmann R. 2004. Modified nucleotides at the $5^{\prime}$ end of human U2 snRNA are required for spliceosomal E-complex formation. RNA 10: 1925-1933.

Esguerra J, Warringer J, Blomberg A. 2008. Functional importance of individual rRNA $2^{\prime}$-O-ribose methylations revealed by high-resolution phenotyping. RNA 14: 649-656. 
Ganot P, Jády BE, Bortolin ML, Darzacq X, Kiss T. 1999. Nucleolar factors direct the 2'-O-ribose methylation and pseudouridylation of U6 spliceosomal RNA. Mol Cell Biol 19: 6906-6917.

Graveley BR, Brooks AN, Carlson JW, Duff MO, Landolin JM, Yang L, Artieri CG, van Baren MJ, Boley N, Booth BW, et al. 2011. The developmental transcriptome of Drosophila melanogaster. Nature 471: 473-479.

Huang ZP, Zhou H, Qu LH. 2005. Maintaining a conserved methylation in plant and insect U2 snRNA through compensatory mutation by nucleotide insertion. IUBMB Life 57: 693-699.

Huang C, Karijolich J, Yu YT. 2011. Post-transcriptional modification of RNAs by artificial Box H/ACA and Box C/D RNPs. Methods Mol Biol 718: 227-244.

Hüttenhofer A, Kiefmann M, Meier-Ewert S, O’Brien J, Lehrach H, Bachellerie JP, Brosius J. 2001. RNomics: An experimental approach that identifies 201 candidates for novel, small, non-messenger RNAs in mouse. EMBO J 20: 2943-2953.

Jack K, Bellodi C, Landry DM, Niederer RO, Meskauskas A, Musalgaonkar S, Kopmar N, Krasnykh O, Dean AM, Thompson SR, et al. 2011. rRNA pseudouridylation defects affect ribosomal ligand binding and translational fidelity from yeast to human cells. Mol Cell 44: 660-666.

Jády BE, Kiss T. 2001. A small nucleolar guide RNA functions both in 2 '$O$-ribose methylation and pseudouridylation of the U5 spliceosomal RNA. EMBO J 20: 541-551.

Jády BE, Darzacq X, Tucker KE, Matera AG, Bertrand E, Kiss T. 2003. Modification of Sm small nuclear RNAs occurs in the nucleoplasmic Cajal body following import from the cytoplasm. EMBO $J$ 22: $1878-1888$.

Jády BE, Ketele A, Kiss T. 2012. Human intron-encoded Alu RNAs are processed and packaged into Wdr79-associated nucleoplasmic box H/ACA RNPs. Genes Dev 26: 1897-1910.

Karijolich J, Yu YT. 2010. Spliceosomal snRNA modifications and their function. RNA Biol 7: 192-204.

Kiss AM, Jády BE, Darzacq X, Verheggen C, Bertrand E, Kiss T. 2002. A Cajal body-specific pseudouridylation guide RNA is composed on two box H/ACA sno-RNA-like domains. Nucleic Acids Res 30: 4643-4649.

Kiss AM, Jády BE, Bertrand E, Kiss T. 2004. Human box H/ACA pseudouridylation guide RNA machinery. Mol Cell Biol 24: 5797-5807.

Lapeyre B. 2005. Conserved ribosomal RNA modification and their putative roles in ribosome biogenesis and translation. In Topics in current genetics: Fine-tuning of RNA functions by modification and editing (ed. Grosjean H), Vol. 12, pp. 263-284. Springer, Berlin.

Lestrade L, Weber MJ. 2006. snoRNA-LBME-db, a comprehensive database of human H/ACA and C/D box snoRNAs. Nucleic Acids Res 34: D158-D162.

Liang XH, Liu Q, Fournier MJ. 2007. rRNA modifications in an intersubunit bridge of the ribosome strongly affect both ribosome biogenesis and activity. Mol Cell 28: 965-977.

Liang XH, Liu Q, Fournier MJ. 2009. Loss of rRNA modifications in the decoding center of the ribosome impairs translation and strongly delays pre-rRNA processing. RNA 15: 1716-1728.

Liu JL, Wu Z, Nizami Z, Deryusheva S, Rajendra TK, Gao H, Beumer KJ, Carroll D, Matera AG, Gall JG. 2009. Coilin is essential for Cajal body organization in Drosophila melanogaster. Mol Biol Cell 20: $1661-1670$.

Ma X, Zhao X, Yu YT. 2003. Pseudouridylation ( $\Psi)$ of U2 snRNA in S. cerevisiae is catalyzed by an RNA-independent mechanism. EMBO J 22: 1889-1897.

Ma X, Yang C, Alexandrov A, Grayhack EJ, Behm-Ansmant I, Yu YT. 2005. Pseudouridylation of yeast U2 snRNA is catalyzed by either an RNA-guided or RNA-independent mechanism. EMBO J 24: 2403-2413.

Massenet S, Motorin Y, Lafontaine DL, Hurt EC, Grosjean H, Branlant C. 1999. Pseudouridine mapping in the Saccharomyces cerevisiae spliceosomal U small nuclear RNAs (snRNAs) reveals that pseudouridine synthase Pus1p exhibits a dual substrate specificity for U2 snRNA and tRNA. Mol Cell Biol 19: 2142-2154.

Maxwell ES, Fournier MJ. 1995. The small nucleolar RNAs. Annu Rev Biochem 35: 897-934.

Myslinski E, Branlant C, Wieben ED, Pederson T. 1984. The small nuclear RNAs of Drosophila. J Mol Biol 180: 927-945.

Nizami Z, Deryusheva S, Gall JG. 2010a. The Cajal body and histone locus body. Cold Spring Harbor Persp Biol 2: a000653.

Nizami ZF, Deryusheva S, Gall JG. 2010b. Cajal bodies and histone locus bodies in Drosophila and Xenopus. Cold Spring Harbor Symp Quant Biol 75: 313-320.

Ofengand J, Bakin A. 1997. Mapping to nucleotide resolution of pseudouridine residues in large subunit ribosomal RNAs from representative eukaryotes, prokaryotes, archaebacteria, mitochondria and chloroplasts. J Mol Biol 266: 246-268.

Richard P, Darzacq X, Bertrand E, Jády BE, Verheggen C, Kiss T. 2003. A common sequence motif determines the Cajal body-specific localisation of box H/ACA scaRNAs. EMBO J 22: 4283-4293.

Smith CM, Steitz JA. 1997. Sno storm in the nucleolus: New roles for myriad small RNPs. Cell 89: 669-672.

Tortoriello G, Accardo MC, Scialo F, Angrisani A, Turano M, Furia M. 2009. A novel Drosophila antisense scaRNA with a predicted guide function. Gene 436: 56-65.

Tycowski KT, You ZH, Graham PJ, Steitz JA. 1998. Modification of U6 spliceosomal RNA is guided by other small RNAs. Mol Cell 2: 629-638.

Tycowski KT, Shu MD, Kukoyi A, Steitz JA. 2009. A conserved WD40 protein binds the Cajal body localization signal of scaRNP particles. Mol Cell 34: 47-57.

Venteicher AS, Abreu EB, Meng Z, McCann KE, Terns RM, Veenstra TD, Terns MP, Artandi SE. 2009. A human telomerase holoenzyme protein required for Cajal body localization and telomere synthesis. Science 323: 644-648.

Wu G, Xiao M, Yang C, Yu YT. 2011. U2 snRNA is inducibly pseudouridylated at novel sites by Pus7p and snR81 RNP. EMBO J 30: 79-89.

Yang C, McPheeters DS, Yu YT. 2005. $\Psi 35$ in the branch site recognition region of U2 small nuclear RNA is important for pre-mRNA splicing in Saccharomyces cerevisiae. J Biol Chem 280: 6655-6662.

Yu Y-T, Shu MD, Steitz JA. 1998. Modifications of U2 snRNA are required for snRNP assembly and pre-mRNA splicing. EMBO $J$ 17: 5783-5795.

Yu Y-T, Terns RM, Terns MP. 2005. Mechanisms and functions of RNA-guided RNA modification. In Topics in current genetics: Fine-tuning of RNA functions by modification and editing (ed. Grosjean H), Vol. 12, pp. 223-262. Springer, Berlin.

Zhao X, Yu YT. 2004. Pseudouridines in and near the branch site recognition region of U2 snRNA are required for snRNP biogenesis and pre-mRNA splicing in Xenopus oocytes. RNA 10: 681-690.

Zhao X, Yu YT. 2007. Incorporation of 5-fluorouracil into U2 snRNA blocks pseudouridylation and pre-mRNA splicing in vivo. Nucleic Acids Res 35: 550-558.

Zhao X, Li ZH, Terns RM, Terns MP, Yu YT. 2002. An H/ACA guide RNA directs U2 pseudouridylation at two different sites in the branchpoint recognition region in Xenopus oocytes. RNA 8: 15151525. 

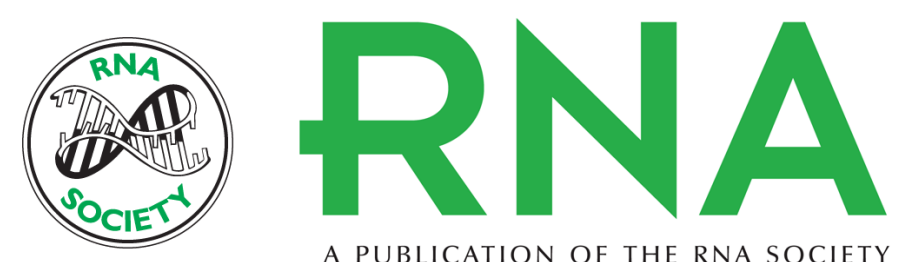

A PUBLICATION OF THE RNA SOCIETY

\title{
Novel small Cajal-body-specific RNAs identified in Drosophila: probing guide RNA function
}

\author{
Svetlana Deryusheva and Joseph G. Gall
}

RNA 2013 19: 1802-1814 originally published online October 22, 2013

Access the most recent version at doi:10.1261/rna.042028.113

\section{References This article cites 27 articles, 6 of which can be accessed free at: http://rnajournal.cshlp.org/content/19/12/1802.full.html\#ref-list-1 \\ Creative This article is distributed exclusively by the RNA Society for the first 12 months after the Commons full-issue publication date (see http://rnajournal.cshlp.org/site/misc/terms.xhtml). After 12 License months, it is available under a Creative Commons License (Attribution-NonCommercial 3.0 Unported), as described at http://creativecommons.org/licenses/by-nc/3.0/.}

Email Alerting Receive free email alerts when new articles cite this article - sign up in the box at the Service top right corner of the article or click here.

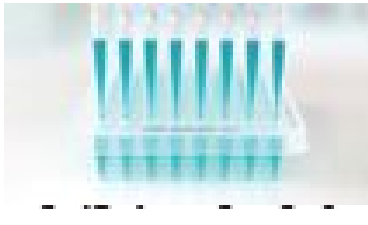

\section{Providing Precise Solutions for} your research.

To subscribe to RNA go to:

http://rnajournal.cshlp.org/subscriptions 